\title{
The Compliance of Birzeit University Toward Green Economy Culture Through Students' Perspective and Attitude in Light of University of Indonesia's World Green Metric (UIWGM)
}

\author{
Mohammad Eid ( Hussein ) \\ Departement of Educational leadership and Foundations \\ Prof Mohammad Saleem AlZboon \\ The University of Jordan
}

\begin{abstract}
The sustainable development concept is currently considered as a lifestyle for universities to compete with each other on global ranking metrics such as the University of Indonesia's World Green Metric (UIWGM). In 2018, Birzeit University was ranked first in Palestine because of its efforts in improving green operations for the current and upcoming future. Due to the fact that the human source is considered the main key in sustainable development, it has been decided to interview 30 students to measure how aware they are toward the universities' Green Economy and analyzing their attitude toward the issue. This research examines the awareness of students at Birzeit University toward Green Economy (Green operation) and their compliance toward it. The theoretical part was constructed on the sustainable development method and how the integrated relationship between Green Economy and education can enhance the behavioral and academic career. With the use of observation and analysis, 30 interviews were conducted with students to measure their understanding of the Green Economy concept, along with their satisfactions on some major functions the university provides like cooling and heating systems, cleanenvironment transportation tools. It has been managed to provide some recommendations to follow to keep the university competing with the other Palestinian and international universities on the UI World Green Metric ranking.
\end{abstract}

Keywords: Sustainable Development, Green Economy, Birzeit University, Enhancement, UIWGM, Environmental Education

DOI: $10.7176 / \mathrm{JEP} / 11-3-09$

Publication date: January $31^{\text {st }} 2020$

\section{Introduction}

As a response to growing concerns and developments about the effect of human society on the natural environment and its resources, the idea of sustainable development was introduced. The Brundtland Commission (formally the International Commission on Environment and Development) introduced the concept of sustainable development in 1987 "Development that meets the needs of the present without compromising the ability of future generations to meet their own needs' (Brundtland, 1987). This definition recognizes that while development is required to fulfill human needs and improve the quality of life, it must occur without compromising the natural environment's ability to meet present and future needs.

Higher education institutions, colleges, and universities should see themselves as members of society in the sense of education and foster principles of business that support human capital. The social factor (Human)'s impact on sustainability development inside Birziait University and its integrity with Green Economy will be the major objective of this study. Birzeit University was ranked the first among the Palestinian universities based on the UI World Green Metric (UIWGM, 2018). This research will examine the compliance of Birzeit students toward Green operations that the university provides.

Research Problem

It has been noticed that there is a lack of awareness in green operations among college students based on previous experience of dealing with university students at all levels at Al Quds University. Such a problem will be discussed in this research, handling the awareness of Birzeit University's students and their compliance with the Green Economy and sustainable development.

\section{Research Questions}

The questions of this research are as follows:

1. Are Birzeit University's students aware of the Green Economy concept considering them the social factor of the study?

2. What is their participation to improve the Birzeit university ranking level in UI World Green Metric to compete with international universities? 


\section{Research Objectives}

The research aims to measure the knowledge of Birzeit students in Green Economy operation and culture to enhance the development process and improve the lifestyle.

\section{Significance of Study}

This study is considered as the first Palestinian research discussing the education process and its relation with the Green Economy structure. It is hoped that this research will be used as a reference for the higher education institution around Palestine.

\section{Literature Review}

\section{Sustainable Development Factors:}

Three major factors are taken into consideration when discussing the role of sustainable development at any level, as these social, economic, and environmental social might enhance the development process of any organization as discussed later.

\section{Social Sustainability}

Social sustainability aims to maintain social capital by investing and developing services that form our society's structure. The term supports a broader world view of populations, traditions, and globalization. This means protecting future generations and understanding that what we are doing will influence others and the environment. Social sustainability focuses on maintaining and improving social quality with ideas like unity, reciprocity and fairness, and the value of people-to-people relationships. Legislation, information and shared ideas on equality and rights can encourage and support it. Social sustainability incorporates the concept of sustainable development as defined by the goals of the sustainable development of the United Nations. The theory of sustainable development addresses social and economic improvement which protects the environment and promotes equality and therefore mutually depends on the economy and society, and the ecological system (Diesendorf, 2000).

\section{Economic Sustainability}

The goal of economic sustainability is to keep the resources intact. If social sustainability aims to increase social equality, the goal of economic sustainability is to increase living standards. This is related to the effective use of assets in the corporate context to sustain the productivity of the organization over time. As the UK Government has stated (Annual Report 2000, January 2001):

"Maintaining high and stable levels of economic growth is one of the key objectives of sustainable development. Abandoning economic growth is not an option. But sustainable development is more than just economic growth. The quality of growth matters as well as the quantity".

Critics of this model acknowledge that the cost of damage to the earth in market prices is not a major gap in modern accounting practices (Hawking, 2010). A more recent economic approach recognizes that ecological and social components are limited to this model. A new economy includes natural capital (ecological systems), social capital (people-to-people relations) and questions of the slogan of capital that constant growth is good and better if it avoids harming the ecological and human system (Benn et al., 2014).

Environmental Sustainability

Environmental sustainability aims at improving human well-being by protecting natural capital (e.g. soil, air, water, minerals, etc.). Environmentally sustainable policies and programs are identified by ensuring that the needs of the population are met without the risk of undermining future generations' needs. Environmental sustainability, as Dunphy, Benveniste, Griffiths and Sutton (2000) explained, examines how companies can produce positive economic results without harming the environment in the short or long term. According to Dunphy et al. (2000), an environmentally sustainable company aims to combine all four sustainability elements, and each needs to be treated equally to achieve this goal.

The theory of the four pillars of sustainability states that to solve full sustainability problems about all four pillars, it is necessary to maintain sustainability. While these which overlap in some situations, it is important to identify the specific type of green business to concentrate on, as there are unique characteristics of the four forms. Companies need to make a strategic decision to integrate the chosen strategy successfully into their policies and procedures.

\section{Green Economy and Sustainable Development}

Recently, significant progress has been made through international conferences and studies to take advantage of sustainable development opportunities in the face of climate change threats, earth's limited carrying capacity, and declining habitats. In 2015, the UN General Assembly decided on Sustainable Development Goals to direct its forward-looking 2030 Agenda. (UN, 2015)

Sustainable development emphasizes the production of natural, social and economic capital, as all of which are vital to the needs of present and future generations. Still, the effect on global environmental developments has been minimal given the concept's penetration into many segments of society and the growth of environmental policies worldwide. Focusing on environmental protection and negative externalities, bottlenecks in the way 
sustainable development have been addressed in practice to provide a basis for understanding the emergence of the Green Economy concept.

Since the last global economic crisis has occurred, the Green Economy has gained attention as a term that can transcend the connotation of environmental protection as a cost factor that slows down economic development and puts the environment and the economy into a positive relationship in which the environment becomes an advantage rather than a constraint and new driving force for economic development. Sustainability remains a critical longterm objective, but the Green Economy provides a roadmap to sustainable development.

The Green Economy idea has grown to emphasize the significance of including social aspects, and many organizations are now referring to an inclusive Green Economy. The Green Economy is a key feature of promoting investment in specific areas often commonly referred to as green sectors that either preserve and sustain natural resources or improve their usage efficiency (Rio, 2012).

Like any other public investment, such investments will lead to job growth, income generation and development of new markets but with lower emissions, resource depletion and contamination of the environment. While each country has its national requirements and the design of a Green Economy and related policies may differ, key features of the greening process can be identified as follows:

(i) An increase in the proportion of green sectors contributing to the gross domestic product and the population of a country employed in those sectors.

(ii) Decoupling economic growth from the use of energy and the impact on the environment.

(iii) Increased public and private spending in green sectors.

(iv) A shifting composition of aggregate demand, increasing the proportion of environmentally friendly products and services. Building on the UNEP study towards Green Economy's policy areas that provide crucial conditions for the transition of a Green Economy include: (i) Promoting innovation and expenditure in areas stimulating the Green Economy (e.g. technology, infrastructure or the infant industry); (ii) Reduce government spending in areas that deplete natural capital by eliminating subsidies that are harmful to the environment; (iii) Setting up sound regulatory frameworks that define rights, opportunities, minimum standards and prohibit the most dangerous types of conduct and substances; (iv) Addressing environmental externalities and current market deficiencies through the use of taxes and market-based mechanisms to encourage green investment and innovation; and (v) Strengthening international governance in areas where economic activity is governed by international and multilateral frameworks in addition to national legislation.

Depending on their current level of development, countries have different capacities to initiate and implement policy reform and cope with transformative change. Other supporting actions are; therefore, needed to increase capacity and strengthen institutions, provide training and skill enhancement to the workforce, and improve general education on sustainability.

\section{Green Economy}

The position of Green Economy is seen in Sustainable Consumption and Production and Resource, Efficiency for Sustainable Development. Sustainable Consumption and Production aimed at improving production processes and consumption practices to reduce the consumption of resources, waste generation and pollution throughout the life cycle of processes and goods. Thus, Resource Efficiency relates to how resources are used to provide value to society and aims at reducing the amount of energy and emissions and waste produced by-product or service unit. The Green Economy provides a macro-economic approach to sustainable economic growth with a central focus on investments, employment, and skills.

\section{Education and Green Economy}

Higher education plays a key role in both Green Economy growth and sustainable development. This does not necessarily mean that the Green Economy and the drive for sustainable development are dormant phenomena in this partnership because they also affect the way higher education reacts to the old and new problems, driving change in these institutions. It is, therefore, necessary that higher education is prepared to engage the Green Economy agenda in the light of sustainable development, eradication of poverty, prosperity and job creation. Not only must jobs be developed, but also they must be maintained through the role of higher education in re-skilling and staying on the cutting edge in terms of research and innovation that tackle issues at the root of Green Economy and sustainable development agendas.

These include, but are not limited to, adaptation and mitigation of climate change, as well as moving away from a resource-intensive development environment to one that uses less energy. Therefore, as the higher education wheel turns in response to the Green Economy transition and sustainable development phenomenon, it activates the wheels of Green Economy and sustainable development which, in turn, will signal a continuous movement in the three wheels showing a contextually reflexive relationship between higher education and these development paths. The Green Economy is characterized as low carbon, resource-efficient and socially inclusive. In a Green Economy, growth in employment and income is driven by public and private investment in such economic activities, infrastructure and assets that allow for reduced carbon emissions and pollution, increased energy and 
resource efficiency, and prevention of biodiversity and ecosystem services losses.

Such green investments must be allowed and funded by targeted public spending, policy reforms, and tax and regulatory changes. UN Environment promotes a path of development that considers natural capital as a critical economic asset and a source of public benefits, especially for the poor whose livelihoods depend on natural resources. The notion of a Green Economy does not replace sustainable development but creates a new focus on the economy, expenditure, resources and infrastructure, jobs and skills and positive social and environmental outcomes across Asia and the Pacific.

\section{The relationship between EE, ESD and ED}

The relationship between environmental education, education for sustainable development and education for development is complex, and the three sometimes display more similarities than differences. The three concentrate on behavioral change through awareness and the fostering of beliefs, behaviors, and understanding. Respect for yourself, respect for others, respect for the world we live in and respect for the earth is a core value advocated by the three industries. A closer examination of each field, however, indicates that each has a primary objective or emphasis which distinguishes it from the other.

Environmental education is focused on the idea that human development has seriously detrimental effects on the natural environment and its primary objective which is to protect and preserve the environment, including natural habitats and ecosystems. The primary concern of development education is to reduce poverty, promote social justice and improve people's quality of life. It addresses fundamental human needs and links actions locally and globally.

Development education focuses on interdependence and interrelationship between people from a global and local viewpoint but history does not extend this to the interdependence of ecosystems or specific environmental concerns. DE focuses primarily on human rights, social injustice, economic exploitation, and global citizenship issues. It is about developing the awareness, understanding, skills, attitudes, values, and behaviors needed to enable people to critically examine the world, its creation and act to make it a fairer and more equal place. It has a lot to do with other social and political education types (Council of Europe, 2012). Human rights education, peace education, multicultural education, race and ethnicity education, environmental education, and eventually citizenship education intersect with development education features and concerns, but each has its own distinct character and emphasis.

The primary concern of education for sustainable development is to enhance people's quality of life without harming the environment. Therefore, although all three educations have a lot in common, they vary in their primary objective. The partnership between ESD and other educational sectors is the topic of ongoing discussion with the latter, which often considers ESD as part of their education. What is more, what many consider to be the closest field to ESD- environmental education- is not generally happy with being seen as equal to ESD. Some agree that ESD will cover all these educational sectors to a certain degree and, with sustainable development being increasingly important in policy and educational contexts, it will be appropriate for each of these sectors and their practitioners to examine the commonalities between them more closely.

Sustainable development education extends to include a strong environmental perspective on the social and human rights element of DE and other educational sectors. ESD has many parallels with DE and discusses issues like climate change, energy scarcity, and water pollution, the need to protect biodiversity, poverty alleviation and human rights. Different methodologies are also used by ESD and DE, including critical thinking and problem solving, experiential learning, role play, directed analysis, conversation, future thinking, and participatory decision making. ESD also helps to relate people's lives globally, develop the world and allows us to link our activities locally to the needs and management of the earth and its people.

The underlying principles of ESD as articulated by UNESCO underline the importance of respect and care for life in all its various forms, where this includes the conservation and preservation of the earth's habitats, respect for human dignity and human rights, respect for future generations' rights and respect for cultural diversity. (UNE, 2012)

Can we say that ESD is the umbrella for many of the other educations or is ESD an aspect of all these educations based on the inter-sectorial relationships mentioned above? This question is likely to require further discussion, but we can propose that these types of education begin to identify areas of commonality with each other in the future, begin to work more collaboratively in areas of the common good and work more closely toward achieving their objectives. Each sector may have an ultimately different objective, but working together to achieve common good areas is likely to result in a more strategic approach and more beneficial outcomes. Sustainable development education can provide space for the creation of this collaborative work.

\section{Methodology}

Universities have a very important issue of sustainability. This situation relates to the size of the area, the number of students, academics, administrative staff, their excessive energy, and materials consumption. Universities have major effects on the environment and culture, either explicitly or implicitly in relation to these circumstances. 
Several assessment methods have been developed to recognize and measure the effective viability of campuses and universities. The Green Metric Index used in this study was established by the University of Indonesia (UI) in 2010.

This model is one of the most widely used and evaluates campus sustainability. This method uses six main criteria: Structure and Infrastructure (SI), Climate and Energy Change (EC), Waste (WS), Water (WR), Transportation (TR) and Education (ED). Many metrics define each of the six main categories, describing the primary sustainability concerns (UI, 2010).

In this article, due to the use of quantitative analyses, the use of the Green Metric Index as a Sustainable Campus has been assessed by Beirzeit University. Positive and negative conditions were defined in terms of Green Metrics as a result of the new research and suggestions.

In the 2018 edition of the UI GreenMetric World University Rankings, which rates universities by their contribution to environmental sustainability, Birzeit University was ranked as the most sustainable university in Palestine and 305th in the world.

Recently published rankings are based on six categories: Setting and Infrastructure, Energy and Climate Change, Waste, Water, Transportation, and Education, weighing and calculating the efforts of the university in each category to produce a total grade.

Since its establishment in 1924, protecting and preserving the environment has always been one of the main goals of Birzeit University. In the early 1970s, Birzeit University students planted the vast pine and cypress trees and green areas covering 70 percent of the university's campus as part of their community-based graduation requirements.

At the $6^{\text {th }}$ Environmental Management Contest in Saudi Arabia, Birzeit University won first place in 2014. For the efforts to integrate environmental management with the design and operations of its campus, the award was given to the University. The university continues its green efforts today with the construction on the campus of five solar power stations supplying 442 kilowatts and covering 22 percent of the energy needs of the city (Birzeit Website).

\section{Data Analysis}

The adopted approach of this research is an exploratory scanning approach. The source of data included interview results and findings that were made with 30 students (not first-year students) (19 males/ 11 females) inside the university campus. 11 questions were asked and categorized into six criteria's like the following:

\section{Setting and Infrastructure}

Are you satisfied with the campus buildings, classrooms, facilities, and equipment?

How about free areas on the campus? Do you believe that it fits well with a student's population?

Energy and Climate Change

Do all university facilities contain lightning, cooling and warming systems to handle different weather conditions?

Have you or do you know any other students who participated in any green activity inside the campus?

Do students participate in reducing energy consumption? And do students help in developing the energetic system in the university?

\section{Waste}

Do you believe that all students distribute papers, plastic, organic disposals on their specific trash can?

Water

Do students participate in water conservation and water recycling activities' inside the campus?

Do you consider tap water as drinking water or do you just buy mineral water?

\section{Transportation}

Do students usually use bicycles to come to university? Or do they transport between buildings using them? Education

Do you have enough resources and easy access to the needed data to improve your academic process? 


\section{Results and Discussion}

9.1 Setting and Infrastructure

Are you satisfied with the campus buildings, classrooms, and equipment?

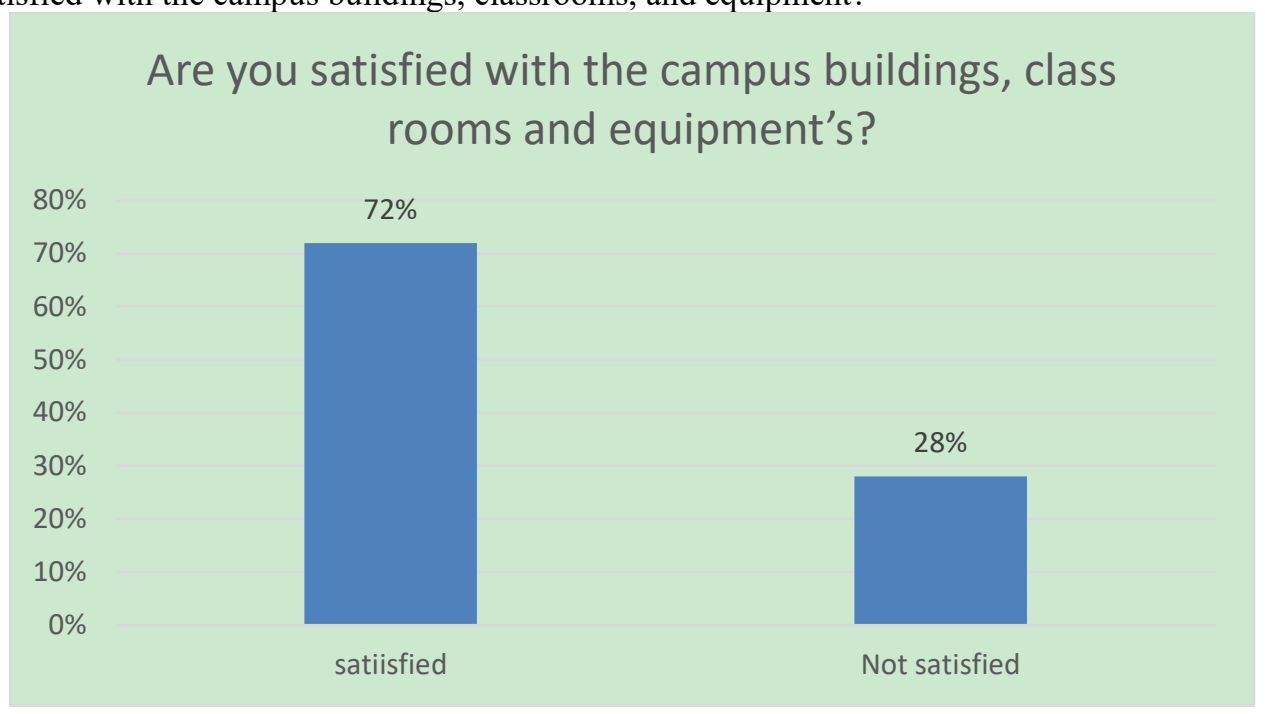

$72 \%$ of students were not satisfied with the university equipment and the campus buildings, their claims were mainly related to the availability of the equipment in which is related to the science laps and the technological tools. Yet, $28 \%$ of students were just fine with the whole infrastructure of the university, considering it better than other universities inside West Bank.

How about free areas and entertainment facilities in the campus? Do you believe they fit well with student's population?

$31 \%$ of the students believe that the available free space inside the university is not enough to handle the student's population, especially at the lunch time when almost all of the students are free and have no classes. Yet, 69\% students believe that the free areas are enough because most of the times students are not located in the same place at the same time. Such scenarios happen rarely as they justified.

\section{Free areas in the campus}

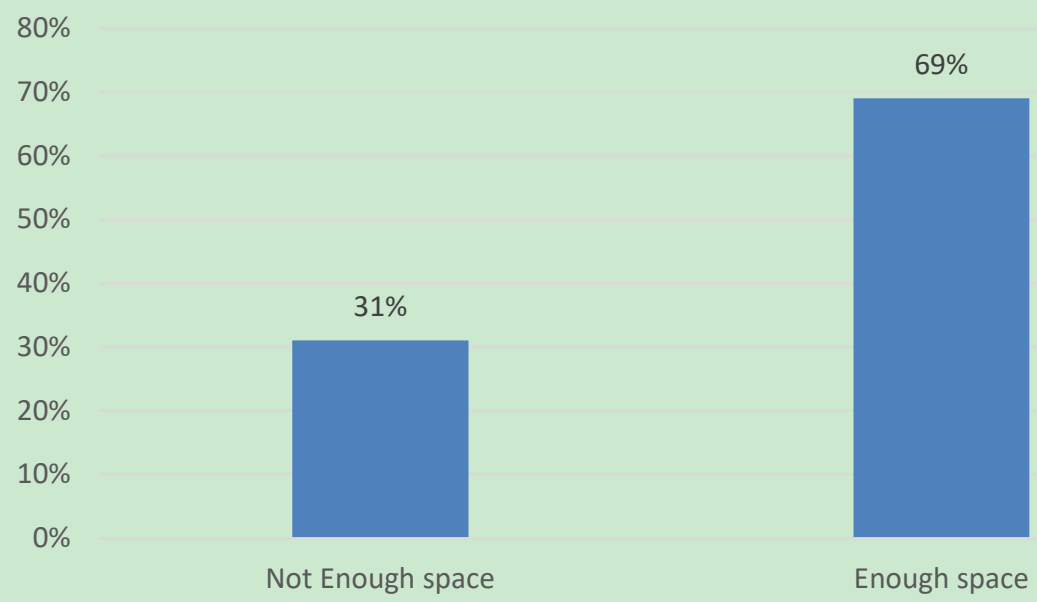




\section{Energy and Climate Change}

Do all university facilities contain lightning, cooling and warming systems to handle different weather conditions?

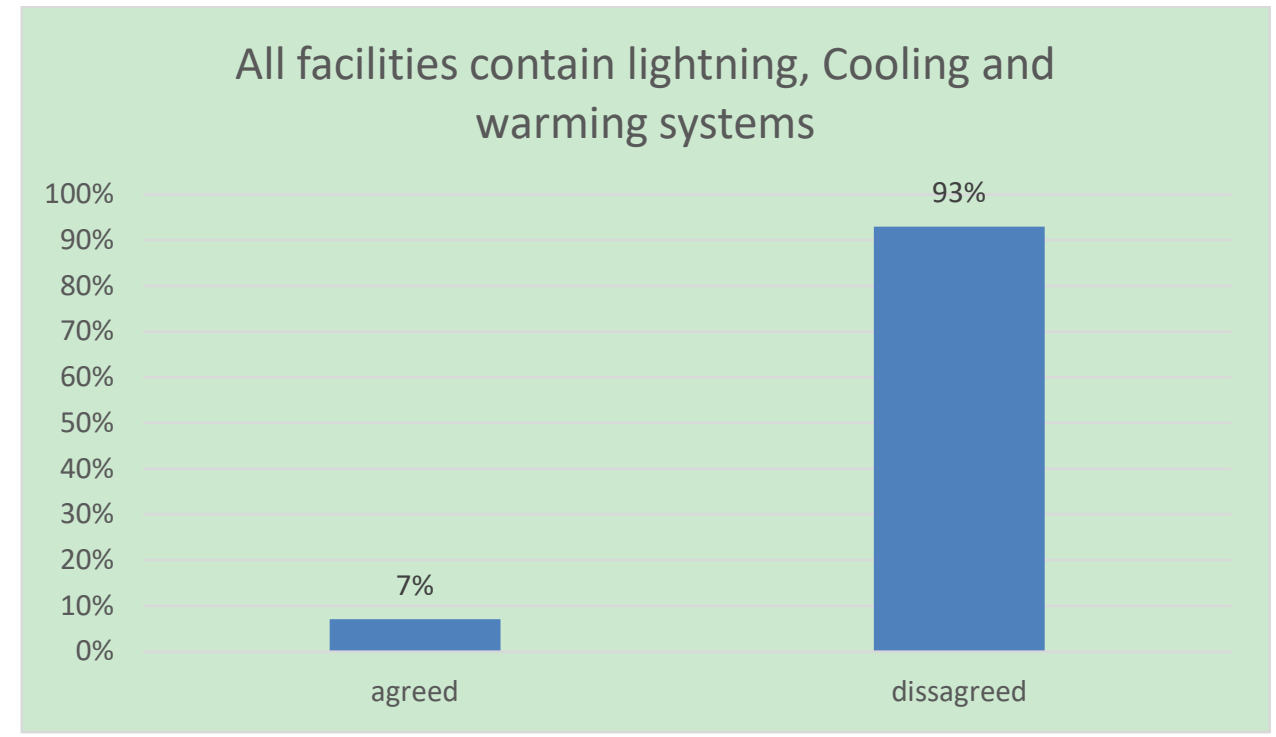

28 students believe that there are not enough lights in some classrooms, especially in winter times. Extra lights or maybe a better distribution of the lights were suggested by this party. Besides, some students mentioned that the heating system in big classrooms is considered insufficient because it does not cover all the areas. On the other hand, 2 students believed that everything is fine regarding the cooling and heating systems and no concerns were mentioned regarding the lightening systems.

Do you know any other students who participated in any green activity inside the campus?

\section{Participation in green activitey}

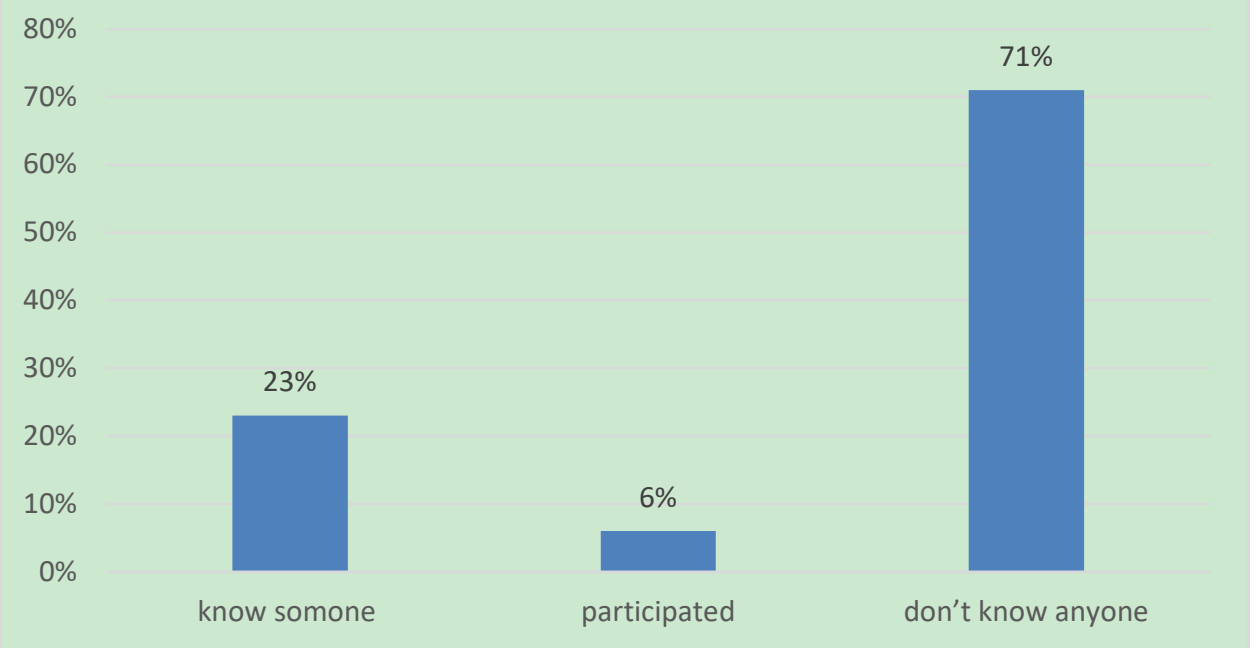

7 students knew other students who participated in green activities events such as farming trees or cleaning the campus. Still, 2 students participated in such events, as both of them were girls and farmed 1 tree 2 years ago. Unfortunately, 21 students did not participate or even met other students who participated in green activities. Such a high percentage would point to the lack of awareness of the importance of green environment.

Do students participate in reducing energy consumption? And do students help in developing the energetic system in the university?

It was surprising that all 30 students answered negatively toward this question as none of them participated in any program related to reducing energy consumption or developing the energetic systems the university owns. 
Waste

Do you distribute papers, plastic, organic disposals on its specific trash can?

\section{Distribute disposals in its specific trash can}
$90 \%$
$80 \%$
$70 \%$
$60 \%$
$50 \%$
$40 \%$
$30 \%$
$20 \%$
$10 \%$
$0 \%$

$80 \%$

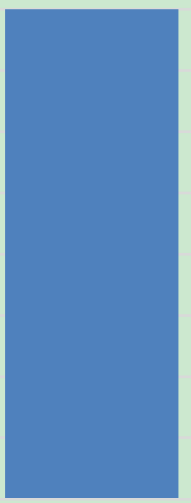

Done Distribute

6 students out of the 30 do distribute papers; plastic, organic disposals on its specific trash can, while 24 of them are not committed to the distribution process. Yet, some of them claimed that they have done it sometimes, especially if they have plastic water bottles or the plastic trash can is near them.

This result is because of the lack of awareness among the students about the importance of trash disposal distribution as it is considered the first step of any recycling project.

Water

Do students participate in water conservation and water recycling activities inside the campus?

\section{participate on Water conservation and Water recycling activities}

$$
\begin{array}{r}
100 \% \\
90 \% \\
80 \% \\
70 \% \\
60 \% \\
50 \% \\
40 \% \\
30 \% \\
20 \% \\
10 \% \\
0 \%
\end{array}
$$

$13 \%$

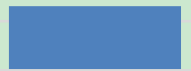

participated
$87 \%$

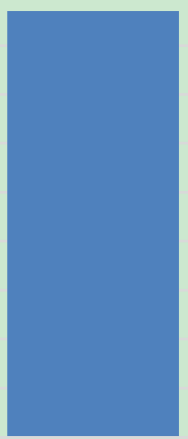

Did not participate

4 students stated that they have participated in a water recycling project as one of them is doing his graduation project in a related topic, while the rest were volunteered in water consumption campaign inside the campus. On the other hand, 26 students said that they have never participated in any water consumption activity inside or even outside the university.

Do you consider tap water as drinking water or do you just buy mineral water?

5 students said that they have drunk from tap water before but they still prefer to use mineral water over tap water as a habit. The other 25 students rejected the idea of drinking from the tap water justifying it by calling it washing water, not drinkable water. 


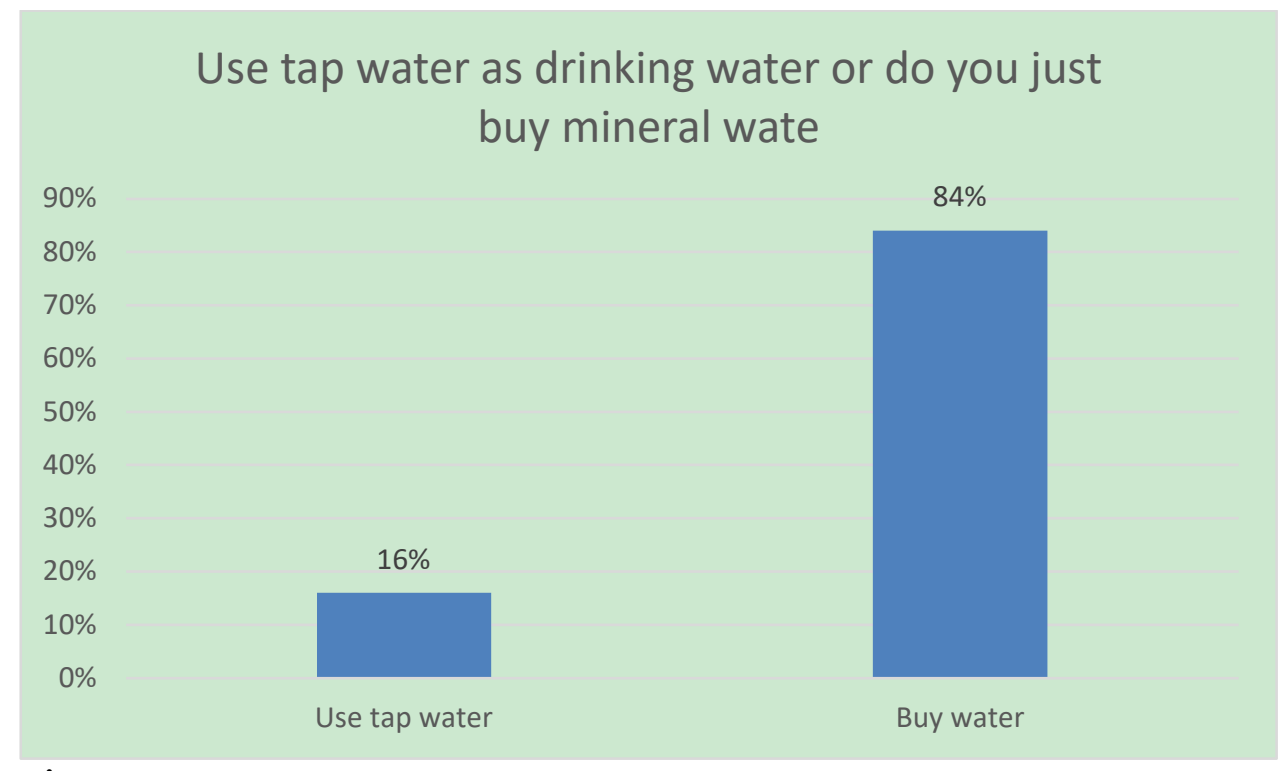

Transportation

Do students usually use bicycles to come to university or do they transport among buildings using them?

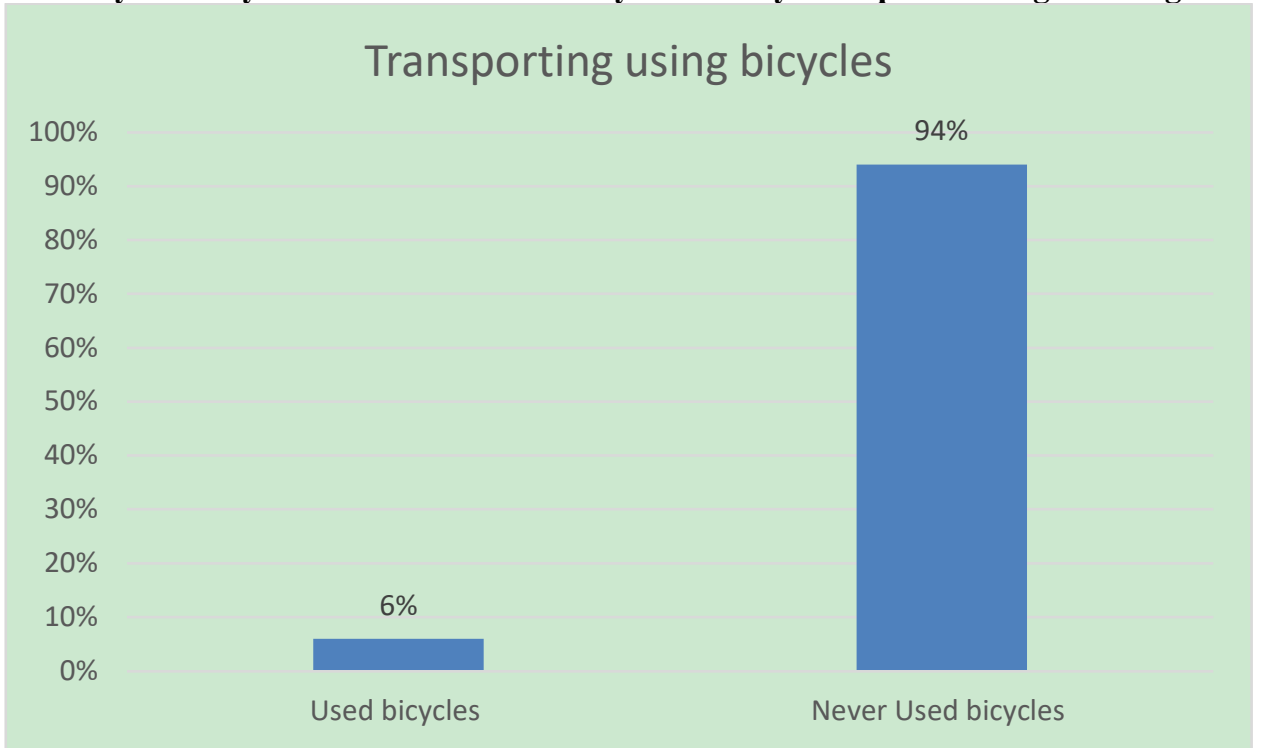

2 students claimed that they have used bicycles before and both of them were male and used their friends' bicycles instead of their own, as one of them said that it was a debate between him and his friend, and he would not try it again. The other 28 students said that it is not culturally acceptable for college students to use bicycles to transport to or in between university's facilities. 


\section{Education}

Do you have enough resources and easy access to the required data to improve your academic process?

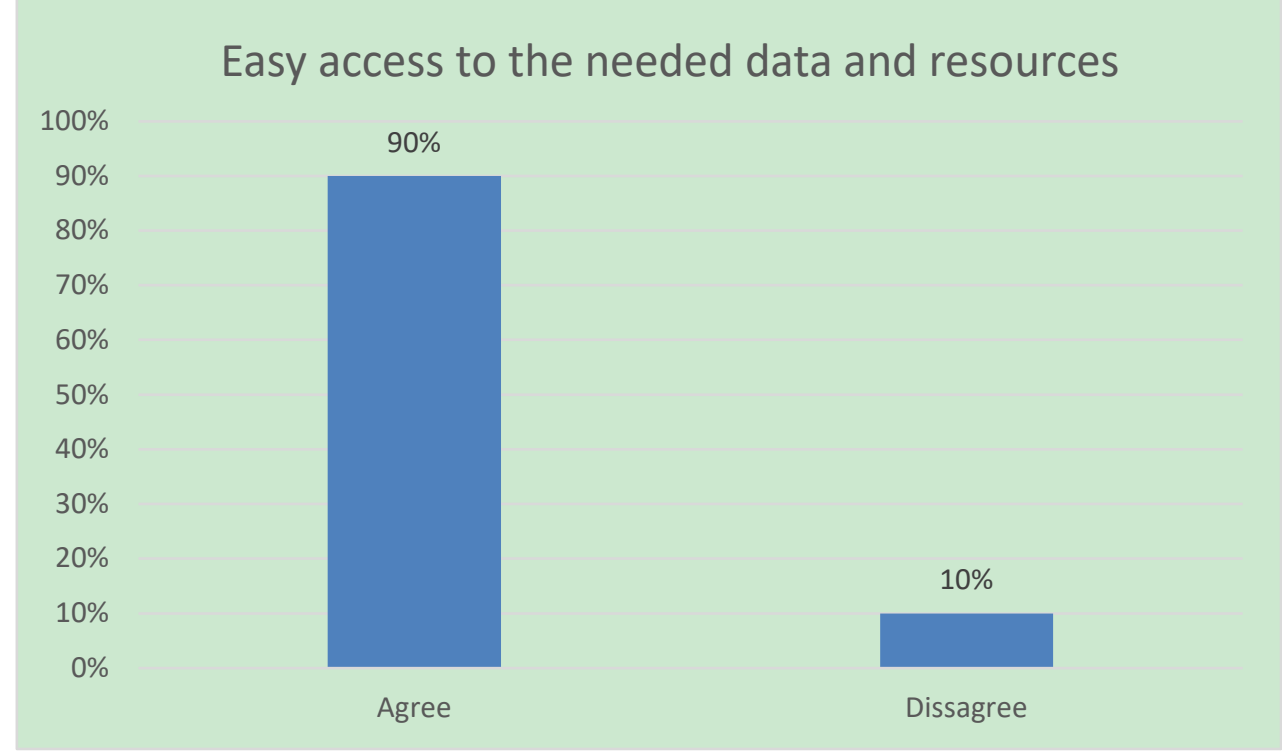

27 students believed that they can easily access all the required facilities inside the universities at all the working days within the roles and structures of the universities' upper management. Libraries and computers connected to the internet are available to use. Although they agreed on the availability of the resources, they insisted that most of the equipment need to be upgraded to compete with the world's new technologies. On the other hand, 3 students stated that it is hard to consider the university lap centers as advance as it should be, along with the fact that some buildings do not have enough printers for students to use at peak times (Research Submission Periods).

\section{Recommendations}

Based on the previous discussion and results, it is noticed that students suffer from lack of knowledge in Green Economy operations inside Birzeit University due to the neglecting of the university's courses outlines in focusing on sustainable and green development enrollment to enhance students' life and participation in the global sustainable development.

To conclude the current research, the following tips are recommended:

- Sensitizing students on the Green Economy and its operations throughout external courses and implacable models to make students aware of problems such as climate change, water consumption, recycling, and green campus.

- The students represent the social structure of the UI model. This means that as much as they are developed, the university will be in a continuous improvement path.

- It is highly important to consider the technological development in the whole world to compete with the global top universities. Buying new computers and providing better versions of projectors and sound systems will be a plus point for the university to compete with other national and international universities.

- Make more events related to the environment and Green Economy, as such events will attract students to participate and show responsibilities to this kind of topic. If it became a cultural event for the university to plant a tree every year, then the university will be participating in planting thousands of trees a year, and by that, it will help in balancing the $\mathrm{O} 2$ and $\mathrm{CO}$.

- It will be much better if the university took into consideration transportation among the university facilities by healthy tools, such as bicycles and electric scooters.

- The university should pay more attention to the availability of clean tap water and teach the kids that they can use the water if it is filtered well. This will reduce student's expenses in buying mineral water and will by default reduce water consumption.

- Maintain the cooling and heating systems inside the universities facilities is highly important as it has a significant influence on students' academic achievements, especially in large classrooms.

- Having more lights and better distribution of lights inside the university will also enhance the development process of the student's education. In winter times, some students mentioned that they suffer from bad lightening in some rooms.

- The university should use all the methods to encourage students and motivate them to use the right trash 
disposals.

\section{References}

Benn, S, .Edwards, M \& Williams, T. (2014).Organizational change for corporate sustainability, Routledge Benveniste, D, , Griffiths.J \& Sutton,A(2000), Sustainability and sustainable development, Sydney: Allen \& Unwin, chap. 2, 19-37

Birzeit Website, https://www.birzeit.edu/

Hawking, S. (2010). Into the Universe, American Physical Society https://journals.aps.org/collections/stephenhawking

Rio, A. (2012). Sustainable Mountain Development Green Economy and Institutions from Rio 1992 to Rio 2012 and beyond, http://www.fao.org/fileadmin/user_upload/mountain_partnership/docs/LOW_Global_Green_Economy_RI O20.pdf 5.

The Deputy Prime Minister and Secretary of State for the Environment, Transport and the Regions. (2001). Annual Report 2001 the Government's Expenditure Plans 2001-02 to 2003-04. Department of the Environment, Transport, and the Regions Eland House Bressenden Place London SW1E 5DU

UI Website, https://greenmetric.ui.ac.id/

United Nations Agenda. (2015). Mainstreaming the 2030 Agenda for Sustainable Development Interim Reference Guide to UN Country Teams, https://www.undp.org/content/dam/undp/library/MDG/Post2015SDG/UNDP-SDG-UNDG-Reference-Guide-UNCTs-2015.pdf. 